\title{
Sulfur-Containing Compounds: Natural Potential Catalyst for the Isomerization of Phytofluene, Phytoene and Lycopene in Tomato Pulp
}

\author{
Lulu Ma ${ }^{1}$, Cheng Yang ${ }^{1}$, Xin Jiang ${ }^{1}$, Qun Wang ${ }^{1}$, Jian Zhang ${ }^{1,2}$ (1) and Lianfu Zhang ${ }^{1,2, *}$ \\ 1 School of Food Science and Technology, Jiangnan University, Wuxi 214122, China; \\ 6180112053@stu.jiangnan.edu.cn (L.M.); cheng.yang@jiangnan.edu.cn (C.Y.); \\ 6170111022@stu.jiangnan.edu.cn (X.J.); 6190111077@stu.jiangnan.edu.cn (Q.W.); zhangiian0411@163.com (J.Z.) \\ 2 The Food College, Shihezi University, Shihezi 832003, China \\ * Correspondence: lianfu@jiangnan.edu.cn; Tel.: +86-510-85917025; Fax: +86-510-85917025
}

check for updates

Citation: Ma, L.; Yang, C.; Jiang, X.; Wang, Q.; Zhang, J.; Zhang, L. Sulfur-Containing Compounds: Natural Potential Catalyst for the Isomerization of Phytofluene, Phytoene and Lycopene in Tomato Pulp. Foods 2021, 10, 1444. https:// doi.org/10.3390/foods10071444

Academic Editor: Isabel M. Vicario Romero

Received: 28 May 2021

Accepted: 7 June 2021

Published: 22 June 2021

Publisher's Note: MDPI stays neutral with regard to jurisdictional claims in published maps and institutional affiliations.

Copyright: (c) 2021 by the authors. Licensee MDPI, Basel, Switzerland. This article is an open access article distributed under the terms and conditions of the Creative Commons Attribution (CC BY) license (https:// creativecommons.org/licenses/by/ $4.0 /)$.

\begin{abstract}
The effects of some sulfur-containing compounds on the isomerization and degradation of lycopene, phytofluene, and phytoene under different thermal treatment conditions were studied in detail. Isothiocyanates such as allyl isothiocyanate (AITC) and polysulfides like dimethyl trisulfide (DMTS) had the effect on the configuration of PTF (phytofluene), PT (phytoene), and lycopene. The proportion of their naturally occurring Z-isomers (Z1,2-PTF and 15-Z-PT) decreased and transformed into other isomers including all-trans configuration, while Z-lycopene increased significantly after thermal treatment, especially for 5-Z-lycopene. The results showed that increase in heating temperature, time, and the concentration of DMTS and AITC could promote the isomerization reaction effectively to some extent. In addition, 15-Z-PT and the newly formed Z4-PTF were the predominant isomers in tomato at the equilibrium. Unlike the lycopene, which degraded significantly during heat treatment, the isomers of PTF and PT were stable enough to resist decomposition. Moreover, the isomerization of three carotenoids was enhanced, and the bioaccessibility of lycopene increased significantly with the addition of shii-take mushroom containing sulfur compounds, while there was no positive effect observed in that of PTF and PT.
\end{abstract}

Keywords: lycopene; phytofluene; phytoene; sulfur-containing compounds; isomerization

\section{Introduction}

Tomato, as one of the most widely cultivated crops in the world, is rich in phenolic compounds, vitamin C, carotenoids, amino acids, etc. [1]. Tomato and tomato-based products play an important role in diet because of their unique flavor and high nutritional value [2]. Numerous epidemiological studies showed that tomato consumption can reduce the risk of many cancers, including breast and prostate cancer [3,4], as well as chronic diseases such as cardiovascular disease [5] and diabetes [3].

Carotenoids are the most important nutrients in tomato including lycopene, phytofluene $(\mathrm{PTF})$, phytoene (PT), etc. Lycopene is the main carotenoid and responsible for the red color of tomatoes. However, Basu et al. [6] pointed out that the health benefits of consuming tomato and its products may the synergies between lycopene and other ingredients, not only lycopene. As a matter of fact, PTF and PT are also important to human health. In an assessment in Luxembourg, the daily intake of PTF and PT contributed 16\% of total daily carotenoid intake, which was higher than lycopene [7]. Particularly, PTF and PT are strongly present in their cis-isomers in natural plants. Due to their naturally existing cisisomers, the bioavailability and bioaccessibility of them are much higher than lycopene in the same food matrices [8,9]. In addition, PTF and PT are proved to have health-promoting actions, such as antioxidant [10] and anti-inflammatory properties along with a reduced risk of various diseases [11]. Besides, they can protect skin against UV damage as their 
maxima absorption was in the ultraviolet region [12]. However, PTF and PT were less concerned in tomato compared with lycopene.

More than $90 \%$ of lycopene present in natural plants is all-E-lycopene [13], however, there are about $50 \%$ of the total lycopene is $Z$-isomers in human serum and tissues [14]. Lycopene can form many geometric isomers because of the carbon-carbon conjugated double bonds. The most common $Z$-lycopene found in processed tomato matrices including 5-Z-, 9-Z-, and 13-Z-lycopene [15]. Many studies showed that the isomerization of allE-lycopene to higher bioactive Z-lycopene happened during tomato processing [16-19]. More recently, it was found that the addition of some ingredients into tomato showed a great significant to the Z-isomerization of lycopene. Honda, et al. found that some traditional seasonings [20] (e.g., jerk sauce, tapenade, aioli) and food ingredients [21] (e.g., Allium sp., shiitake mushroom) can promote the Z-isomerization reaction of lycopene with thermal treatment. Besides, $\mathrm{Yu}$, et al. [22] combined onions and tomato sauce to promote Z-isomerization of lycopene and increased accessibility of total lycopene. Further research showed that some sulfur-containing compounds, e.g., polysulfides, isothiocyanate, and carbon disulfide, in food enhanced the thermal Z-isomerization. Honda, et al. [23] also discussed the isothiocyanates and polysulfides on the $Z$-isomerization and decomposition of lycopene, $\beta$-carotene, and astaxanthin standard. However, most of these studies focused on the degradation and isomerization of lycopene in tomato and ignored the change of colorless carotenoids with high nutritional value.

In the case of PTF and PT, they are strongly present in their cis-isomers in natural plants. PT major presented as 15-Z-PT, which is synthesized by two molecules of geranylgeranyl diphosphate (C20), and PTF exists as a mixture of several isomers in plants [11]. However, most research just focused on the change of total content and ignored the isomerization of them during thermal treatment. Graziani, et al. [24] found that there was no obvious change in the content of PTF and PT after heating at $100{ }^{\circ} \mathrm{C}$ within $4 \mathrm{~h}$. In the study by Cooperstone et al. [25], the content of PTF and PT unchanged in tangerine tomato after heating at $100{ }^{\circ} \mathrm{C}$ within $180 \mathrm{~min}$. However, Mapelli-Brahm et al. [26] reported that the PTF and PT in orange juice decreased significantly after pasteurizing. There was less information about the isomerization of PTF and PT in tomato and the stability of their isomers during food processing. Moreover, data on their isomeric profile with sulfur-containing compounds during thermal treatment and the bioaccessibility of different isomers were scarce. Thus, the objective of this study was to investigate the effect of different sulfur-containing compounds on the isomerization and degradation of PTF, PT, and lycopene in tomato-oil under different thermal conditions, to help forecast their expected isomeric profiles in food processing. In addition, we combined tomato with shii-take mushroom which containing sulfur compounds [21,27] such as dimethyl trisulfide, dimethyl disulfide, etc., to investigate the effect on isomerization and bioaccessibility of PTF, PT, and lycopene. The results will benefit the food processers and provide information on developing tomato products rich in PTF, PT, and lycopene.

\section{Materials and Methods}

\subsection{Chemicals and Reagents}

The cherry tomatoes (Lycopersicon esculentum var. cerasiforme) IVF3535 were provided by Xinjiang Guannong Fruit \&Antler CO., LTD.; extra virgin olive oil and fresh shii-take mushrooms were purchased at the local supermarket; all-E-lycopene was purchased from Huabei pharmaceutical factory; phytofluene and phytoene(a mixture of $E / Z$ isomers) were purchased from Carotenature, Switzerland; methanol, acetonitrile, and methyltert-butyl ether (MTBE) for chromatography were HPLC grade purchased from Oceanpak, Sweden; ethyl acetate, hexane, methanol, and acetone for extraction were analytical grade purchased from Sinopharm, China. Methyl isothiocyanate (MITC), butyl isothiocyanate (BITC), diallyl disulfide (DADS) and dimethyl trisulfide (DMTS) were purchased from Aladdin, China, and allyl isothiocyanate (AITC) and diallyl trisulfide (DATS) were purchased from J\&K Scientific, China. 
2.2. Effect of the Types of Sulfur-Containing Compounds on the Isomerization and Degradation of $P T F, P T$, and Lycopene

Different types of isothiocyanates (MITC, BITC, AITC) and polysulfides (DADS, DATS, DMTS) were first dissolved in olive oil at a concentration of $20 \mathrm{mg} / \mathrm{g}$, and then $5 \%$ olive oil with or without (control group) sulfur-containing compounds was blended into tomato pulp as a mediator of the $E / Z$-isomerization. The final concentration for isothiocyanates and polysulfides in tomato puree-olive oil mixture was $1 \mathrm{mg} / \mathrm{g}$. Obtained mixture was added into a $20 \mathrm{~mL}$ screw-capped glass bottle and air was purged by nitrogen gas. The mixture was then heated at $80^{\circ} \mathrm{C}$ for $1 \mathrm{~h}$ in a water bath. After thermal treatment, samples were immediately cooled down and stored at $-20^{\circ} \mathrm{C}$ until analysis.

\subsection{Effect of the Concentration of DMTS and AITC on the Isomerization and Degradation of PTF, $P T$, and Lycopene}

One of the polysulfides and isothiocyanates each-DMTS and AITC - were selected to investigate the effect of concentration on the isomerization and degradation during thermal treatment. Briefly, DMTS and AITC were both dissolved in olive oil in the concentration of $4,10,20,40,80$, and $100 \mathrm{mg} / \mathrm{g}$, respectively, then $5 \%$ olive oil was blended into tomato pulp. The concentration of DMTS or AITC in mixture was $0.2,0.5,1,2,4$, and $5 \mathrm{mg} / \mathrm{g}$ in the end. The mixture was then put into a glass bottle, purged of air by nitrogen gas, and heated at $80^{\circ} \mathrm{C}$ for $1 \mathrm{~h}$ in a water bath. After thermal treatment, samples were immediately cooled down and stored at $-20^{\circ} \mathrm{C}$ until analysis.

\subsection{Effect of the Reaction Temperature on the Isomerization and Degradation of PTF, PT,} and Lycopene

One of the isothiocyanates (AITC) and polysulfides (DMTS) each were chosen for further study. DMTS and AITC were dissolved in olive oil at a concentration of $20 \mathrm{mg} / \mathrm{g}$, respectively, and then $5 \%$ olive oil was blended into tomato pulp. The final concentration of DMTS and AITC was $1 \mathrm{mg} / \mathrm{g}$ mixture. Then the mixture was heated at different temperature $\left(40{ }^{\circ} \mathrm{C}, 60{ }^{\circ} \mathrm{C}, 80^{\circ} \mathrm{C}, 100{ }^{\circ} \mathrm{C}, 120^{\circ} \mathrm{C}\right)$ for $1 \mathrm{~h}$. After the thermal treatment, samples were immediately cooled down and stored at $-20^{\circ} \mathrm{C}$ until analysis.

\subsection{Effect of the Reaction Time on the Isomerization and Degradation of PTF, PT, and Lycopene}

DMTS and AITC were dissolved in olive oil at a concentration of $20 \mathrm{mg} / \mathrm{g}$, and then $5 \%$ olive oil was blended into tomato pulp. The final concentration of DMTS and AITC was $1 \mathrm{mg} / \mathrm{g}$ mixture. Then the mixture was heated at $80^{\circ} \mathrm{C}$ for $0,10,20,30,60,90$, and $120 \mathrm{~min}$. After the thermal treatment, samples were immediately cooled down and stored at $-20^{\circ} \mathrm{C}$ until analysis.

\subsection{Preparation of the Tomato and Shii-Take Mushroom Mixture}

Different proportion $(10 \%, 20 \%, 30 \%, 40 \%, 50 \%)$ of shii-take mushroom and $5 \%$ olive oil were added into the tomato pulp. The mixture was homogenized by a food processor and then transferred into a $50 \mathrm{~mL}$ screw-capped glass bottle and air was purged by nitrogen gas. The mixture was then heated at $80^{\circ} \mathrm{C}$ for $1 \mathrm{~h}$ in a water bath. After thermal treatment, samples were immediately cooled down and stored at $-20^{\circ} \mathrm{C}$ until analysis.

\subsection{In Vitro Digestion Procedure}

The in vitro digestion was developed by Yu, et al. [28] with minor modifications. Two g mixtures were weighed into a $50 \mathrm{~mL}$ conical flask. $20 \mathrm{~mL} 0.9 \% \mathrm{NaCl}$ and $2 \mathrm{~mL}$ of porcine pepsin solution $(32 \mathrm{mg} / \mathrm{mL}$ in $0.1 \mathrm{M} \mathrm{HCl}$ ) were added. The $\mathrm{pH}$ was adjusted to 2.0 with $2.5 \mathrm{M} \mathrm{HCl}$, and then the mixture was incubated at $37^{\circ} \mathrm{C}$ for $1 \mathrm{~h}$ at $300 \mathrm{rpm}$ to mimic the gastric digestion. Finally, $9 \mathrm{~mL}$ of porcine bile $(24 \mathrm{mg} / \mathrm{mL}$ in $0.1 \mathrm{M} \mathrm{NaHCO} 3)$ and $4 \mathrm{~mL}$ of pancreatin $\left(12 \mathrm{mg} / \mathrm{mL}\right.$ in $\left.0.1 \mathrm{M} \mathrm{NaHCO}_{3}\right)$ were added, and the $\mathrm{pH}$ was adjusted to 7.0 with $0.25 \mathrm{M} \mathrm{NaOH}$. Mixtures were further incubated at $37^{\circ} \mathrm{C}$ for $2 \mathrm{~h}$ at $300 \mathrm{rpm}$ to mimic digestion. The digesta were centrifuged at $4{ }^{\circ} \mathrm{C}$ for $1 \mathrm{~h}$ at $5000 \mathrm{~g}$, and the aqueous 
micellar phase was collected and passed through $0.22 \mu \mathrm{m}$ cellulose esters filters (Millipore) and stored at $-20^{\circ} \mathrm{C}$ until analysis.

\subsection{HPLC Analysis and Identification of Lycopene, Phytofluene, and Phytoene Isomers}

Isomers of lycopene, PTF, and PT were analyzed by reversed-phase HPLC equipped with a diode array detector (Alliance 2695; Waters Corp., Milford, MA, USA). The method was developed by Cooperstone et al. [25]. The carotenoids were separated using a C30 reversed phase column $(150 \times 4.6 \mathrm{~mm}, 3 \mu \mathrm{m}$; YMC Co, Kyoto, Japan). For the quantification of lycopene, PTF and PT isomers were performed by peak area at 471,348 , and $286 \mathrm{~nm}$, respectively. The identification of lycopene, PTF, and PT isomers was conducted by comparison of their retention times with that of standards and spectroscopic features (Q-ratio for lycopene, \%III/II for PTF, and PT [29]). The quantification of all-E-lycopene, PTF, and PT isomers was determined by their external standard curve, and Z-lycopene was quantified with the same calibration curve of all-E-lycopene standards.

\subsection{Extraction of Carotenoids}

Carotenoids extraction from the tomato [25]: briefly, about $5 \mathrm{~g}$ of the tomato pulp were added into triangle beaker with $20 \mathrm{~mL}$ extraction solvent: $\mathrm{n}$-hexane: methanol: acetone $(2: 1: 1, v / v / v)$, and then stirred $20 \mathrm{~min}$ under the dim light to prevent the degradation of carotenoids. The supernatant was collected by vacuum filtering, and filtered residue was repeated extraction two times until the color faded. The supernatant was combined together and the organic phase which containing carotenoids was separated with separating funnel, and then concentrated by rotary evaporator at $35^{\circ} \mathrm{C}$. The concentrated extraction was dissolved in ethyl acetate and diluted with methanol: $\operatorname{MTBE}(1: 1, v / v)$ to a proper concentration.

Carotenoid extraction from the aqueous micellar phase: $3 \mathrm{~mL}$ of the micellar was extracted three times with $5 \mathrm{~mL}$ of hexane and methanol $(1: 1 \mathrm{v} / \mathrm{v})$. The organic phase was collected and evaporated to dryness under nitrogen and dissolved in $100 \mu \mathrm{L}$ methanol: $\operatorname{MTBE}(1: 1, v / v)$ for the HPLC quantification.

\subsection{Statistical and Data Analysis}

All experiments in this work were carried out in triplicate; the values were presented as means values \pm standard deviation (SD). The statistical significance $(p<0.05)$ was determined by Tukey's multiple comparison test.

\section{Results and Discussion}

\subsection{Profile of Phytofluene, Phytoene, and Lycopene Isomers after Thermal Treatment}

After thermal treatment with sulfur-containing compounds, the profile of PTF, PT, and lycopene in tomato pulp changed markedly as shown in Figure A1. The isomers of PTF, PT, and lycopene were identified by their chromatographic elution order compared with that of standards, and UV-V are spectral features (as illustrated in Figure A2), $\lambda$ max, $\%$ III/II, and Q ratio [29-32]. The details are shown in Table 1. The spectra of cis-isomers exhibit a reduction of fine structure relative to the all-E-isomer, and therefore, we identified the peak of all-E-PTF and all-E-PT as their large number of \%III/II [29,32].

For PTF, we only detected two main peaks in raw tomato pulp (as illustrated in Figure A1), and two new isomers generated after heat treatment. Z1-PTF and Z2-PTF cannot separate from each other, as reported by $\mathrm{Yu}$, et al. [28], so we quantified them as Z1,2-PTF as a whole. The Z1,2-PTF was the most abundant isomer, which accounted for $78 \%$ of PTF in raw tomato pulp. Meanwhile, only one peak of PT was detected and identified as 15-Z-PT because it was the major geometrical isomer in carotenogenic organisms [33]. Interestingly, after thermal treatment, two new isomers (Z1-PT and all$E$-PT) generated in tomatoes, as reported in [32]. Moreover, lycopene was represented in mainly all- $E$ configuration and in raw tomato pulp. For instance, all-E-lycopene accounted for $80.1-86.5 \%$ and the proportion of 5-Z-lycopene was about $6 \%$, the others isomers were 
represented in cis-configuration, which was in accordance with the report of Colle et al. [34] After heating with the sulfur-containing compounds, the peak area of Z-lycopene increased obviously, which indicated that higher amount of Z-lycopene were produced through the trans-cis isomerization of all- $E$-lycopene by the catalysis of sulfur-containing compounds. Yu et al. [22] also found that it was DADS in onion which were responsible for the increased Z-lycopene during heating tomato puree with onion.

Table 1. Identification of isomers of phytofluene, phytoene, and lycopene.

\begin{tabular}{|c|c|c|c|c|c|c|}
\hline \multirow{2}{*}{ Carotenoids } & \multirow{2}{*}{$\begin{array}{l}\text { Retion Time (min) } \\
\text { Observed }\end{array}$} & \multirow{2}{*}{$\begin{array}{c}\lambda \max \\
(\mathrm{nm})\end{array}$} & \multirow{2}{*}{$\begin{array}{c}\% \text { III/II } \\
\text { Observed }\end{array}$} & \multirow{2}{*}{$\begin{array}{c}\% \text { III/II } \\
\text { Reported }\end{array}$} & \multirow{2}{*}{$\begin{array}{c}\text { Q-Ratio } \\
\text { Observed }\end{array}$} & \multirow{2}{*}{$\begin{array}{c}\text { Q-Ratio } \\
\text { Reported }\end{array}$} \\
\hline & & & & & & \\
\hline Z1-PTF & 9.63 & $332,347,364$ & 70.51 & $52.2^{a}, 68.8^{b}$ & - & - \\
\hline Z2-PTF & 9.85 & $332,347,364$ & 78.64 & $82.2^{a}, 70.2^{b}$ & - & - \\
\hline Z3-PTF & 10.44 & $332,347,364$ & 80.65 & $89.3^{a}, 100^{b}$ & - & - \\
\hline All-E-PTF & 11.09 & $331,347,364$ & 82.61 & $91.4^{\mathrm{a}}, 86.5^{\mathrm{b}}$ & - & - \\
\hline Z4-PTF & 11.59 & $331,347,364$ & 78.91 & $90.3^{a}, 77.5^{b}$ & - & - \\
\hline Z1-PT & 8.33 & 286 & - & - & - & - \\
\hline 15-Z-PT & 8.60 & 286 & 9.09 & - & - & - \\
\hline All-E-PT & 9.12 & 286 & 14.35 & $19.05^{\mathrm{a}}$ & - & - \\
\hline 13-Z-LYC & 29.61 & $360,439,464,496$ & - & - & 0.58 & $0.56^{\mathrm{c}}$ \\
\hline 9-Z-LYC & 31.71 & $360,439,465,497$ & - & - & 0.14 & $0.13^{a}$ \\
\hline All-E-LYC & 34.65 & $361,446,472,503$ & - & - & 0.06 & $0.06^{\mathrm{d}}$ \\
\hline 5-Z-LYC & 35.07 & $360,446,472,503$ & - & - & 0.06 & $0.08^{a}$ \\
\hline
\end{tabular}

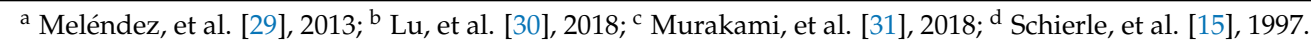

\subsection{Effect of Sulfur-Containing Compounds Types on Isomerization and Degradation of Lycopene, Phytoene, and Phytofluene}

The isomerization and degradation of three different carotenoids in tomato pulp with effect of six types of sulfur-containing compounds after heating at $80{ }^{\circ} \mathrm{C}$ for $1 \mathrm{~h}$ was investigated. The content of PTF, PT, and lycopene was $22.9 \mu \mathrm{g} / \mathrm{g}, 13.0 \mu \mathrm{g} / \mathrm{g}$, and $142.4 \mu \mathrm{g} / \mathrm{g}$, respectively, in the raw tomato pulp. In the control group, the contents of total lycopene, PT, and PTF and the ratios between isomers remained the same with those in raw tomato pulp after heating with olive oil alone at $80^{\circ} \mathrm{C}$ for $1 \mathrm{~h}$. Colle et al. [35] also reported that there was no significant isomerization and degradation of lycopene below $100{ }^{\circ} \mathrm{C}$, and the results reported by Cooperstone et al. [25] indicate that PT and PTF were stable enough under $100{ }^{\circ} \mathrm{C}$ with or without lipids despite being present in cis-configuration.

The ratio of each Z-isomer between three carotenoids changed obviously once the six sulfur-containing compounds were added as catalyst (as illustrated in Tables 2 and 3). As for PTF, the proportion of natural occurring Z1,2-PTF decreased after the sulfur-containing compounds added. Meanwhile, two new Z-peaks, Z3- and Z4-PTF, could be observed. In the research of Meléndez-Martínez et al. [32], they separated six geometrical different isomers of PTF from a natural extract of lycopene-rich tomato. In a comparison of the effects of isothiocyanates and polysulfides, the ratio between PTF isomers was different. In the case of isothiocyanates, the proportion of all-E-PTF increased slightly; Z1,2-PTF mainly converted to Z3- and Z4-PTF. For example, when BITC was added, the proportion of $Z 1$,2-PTF decreased to $31.3 \%$ from $76.5 \%$, and all-E-PTF was about $5 \%$ higher than that of the control group. However, when polysulfides were used, the proportion of Z1,2-PTF and all-E-PTF were significantly decreased $(p<0.05)$ compared to that of the control group.

The same phenomenon was observed for PT. The proportion of 15-Z-PT decreased significantly $(p<0.05)$, while all-E-PT increased with the addition of catalyst. Moreover, the catalytic ability of polysulfides to PT was stronger than isothiocyanates because a new peak Z1-PT could be observed with the effect of polysulfides. Unlike the decomposition of lycopene, there was little degradation of total PTF and total PT in tomato pulp, which indicated that the new formed isomers of PTF and PT were stable enough to resist the degradation with the influence of heating and catalysis; this could be explained by the 
protection of tomato matrix. In the study of Lu et al. [30], there was not any change between the content of PTF and PT isomers in orange juice cv. Cara Cara after thermal treatment, while the content decreased obviously in simulated system.

Table 2. Effects of different sulfur-containing compounds on PTF and PT.

\begin{tabular}{|c|c|c|c|c|c|c|c|c|c|}
\hline \multirow{2}{*}{ Types } & \multirow{2}{*}{$\begin{array}{l}\text { Remaining } \\
\text { PTF (\%) }\end{array}$} & \multicolumn{4}{|c|}{ Proportion of PTF Isomers (\%) } & \multirow{2}{*}{$\begin{array}{l}\text { Remaining } \\
\text { PT (\%) }\end{array}$} & \multicolumn{3}{|c|}{ Proportion of PT Isomers (\%) } \\
\hline & & Z1,2-PTF & Z3-PTF & All-E-PTF & Z4-PTF & & Z1-PT & 15-Z-PT & All-E-PT \\
\hline Control & $104.5 \pm 3.6^{\mathrm{a}}$ & $76.5 \pm 1.1^{\mathrm{a}}$ & - & $23.5 \pm 1.1 \mathrm{abc}$ & - & $98.8 \pm 4.2^{\mathrm{a}}$ & - & $100^{\mathrm{a}}$ & - \\
\hline MITC & $98.3 \pm 0.3^{\mathrm{a}}$ & $28.0 \pm 0.3^{b c}$ & $13.1 \pm 1.6^{b}$ & $28.4 \pm 4.6^{\mathrm{a}}$ & $30.5 \pm 3.2^{c}$ & $97.0 \pm 3.4^{\mathrm{a}}$ & - & $95.7 \pm 2.1^{\mathrm{a}}$ & $4.3 \pm 2.1^{b}$ \\
\hline BITC & $97.14 \pm 2.5^{\mathrm{a}}$ & $31.8 \pm 1.1^{\mathrm{b}}$ & $13.4 \pm 0.5^{\mathrm{b}}$ & $23.6 \pm 0.1^{a b c}$ & $31.2 \pm 1.3^{\mathrm{bc}}$ & $99.9 \pm 2.1^{\text {a }}$ & - & $94.0 \pm 1.3^{\mathrm{a}}$ & $6.0 \pm 1.3^{b}$ \\
\hline AITC & $101.6 \pm 0.8^{\mathrm{a}}$ & $28.1 \pm 0.2^{\mathrm{bc}}$ & $14.3 \pm 0.7^{\mathrm{ab}}$ & $25.1 \pm 0.1^{\mathrm{ab}}$ & $32.5 \pm 0.3^{a b c}$ & $99.8 \pm 0.4^{\mathrm{a}}$ & - & $93.5 \pm 0.1^{\mathrm{a}}$ & $6.5 \pm 0.1^{b}$ \\
\hline DADS & $95.7 \pm 0.1^{\mathrm{a}}$ & $27.8 \pm 1.1^{\mathrm{bc}}$ & $18.2 \pm 0.1^{\mathrm{a}}$ & $17.2 \pm 0.5^{b c}$ & $36.8 \pm 0.5^{a b c}$ & $103.1 \pm 0.3^{\mathrm{a}}$ & $6.7 \pm 0.0^{b}$ & $71.6 \pm 0.1^{\mathrm{b}}$ & $21.7 \pm 0.2^{\mathrm{a}}$ \\
\hline DATS & $98.4 \pm 3.5^{\mathrm{a}}$ & $27.9 \pm 1.2^{b c}$ & $17.1 \pm 0.3^{a b}$ & $15.2 \pm 0.1^{b c}$ & $39.8 \pm 1.6^{\mathrm{ab}}$ & $106.5 \pm 2.1^{\mathrm{a}}$ & $8.1 \pm 1.2^{\mathrm{ab}}$ & $64.1 \pm 4.2^{b c}$ & $27.8 \pm 2.9^{a}$ \\
\hline DMTS & $94.5 \pm 0.2^{\mathrm{a}}$ & $26.9 \pm 0.1^{\mathrm{c}}$ & $17.3 \pm 0.3^{\mathrm{ab}}$ & $14.8 \pm 0.3^{c}$ & $40.9 \pm 0.2^{\mathrm{a}}$ & $102.9 \pm 0.8^{\mathrm{a}}$ & $11.8 \pm 0.1^{\mathrm{a}}$ & $59.9 \pm 0.6^{c}$ & $28.3 \pm 0.5^{\mathrm{a}}$ \\
\hline
\end{tabular}

Data followed by different letters in same column are significantly different $(p<0.05)$. MITC: Methyl isothiocyanate; BITC: butyl isothiocyanate; AITC: allyl isothiocyanate; DADS: diallyl disulfide; DATS: diallyl trisulfide; DMTS: dimethyl trisulfide; Remaining PTF: PTF content in tomato pulp after thermal treatment compared to that of content in the raw tomato pulp; remaining PT: PT content in tomato pulp after thermal treatment compared to that of content in raw tomato pulp.

Table 3. Effects of different sulfur-containing compounds on lycopene.

\begin{tabular}{|c|c|c|c|c|c|c|c|}
\hline \multirow{2}{*}{ Types } & \multirow{2}{*}{$\begin{array}{c}\text { Remaining } \\
\text { Lycopene }(\%)\end{array}$} & \multicolumn{6}{|c|}{ Proportion of Lycopene Isomers (\%) } \\
\hline & & All-E-LCY & Total-cis & $5-Z$ & $9-Z$ & $13-Z$ & Others-cis \\
\hline control & $98.6 \pm 1.3^{\mathrm{a}}$ & $78.5 \pm 0.6^{\mathrm{a}}$ & $21.5 \pm 0.6^{\mathrm{d}}$ & $5.4 \pm 0.8^{\mathrm{d}}$ & $1.8 \pm 0.1^{\mathrm{e}}$ & $8.7 \pm 0.1^{\mathrm{d}}$ & $5.7 \pm 0.0^{b}$ \\
\hline MITC & $84.6 \pm 0.4^{b c}$ & $52.9 \pm 0.5^{b}$ & $47.1 \pm 0.5^{\mathrm{c}}$ & $22.0 \pm 0.6^{\mathrm{a}}$ & $6.4 \pm 0.4^{\mathrm{d}}$ & $9.7 \pm 0.6^{\mathrm{cd}}$ & $9.0 \pm 0.1^{\mathrm{ab}}$ \\
\hline BITC & $86.3 \pm 0.2^{b}$ & $55.3 \pm 2.6^{b}$ & $44.7 \pm 2.6^{\mathrm{c}}$ & $14.3 \pm 0.6^{\mathrm{c}}$ & $7.8 \pm 0.5^{b c d}$ & $9.7 \pm 0.9^{\mathrm{cd}}$ & $12.9 \pm 3.5^{\mathrm{ab}}$ \\
\hline AITC & $81.5 \pm 2.1 \mathrm{bc}$ & $49.2 \pm 0.4^{b c}$ & $50.8 \pm 0.4^{b c}$ & $19.7 \pm 0.2^{a b}$ & $8.7 \pm 0.1^{b c}$ & $10.6 \pm 0.1^{\mathrm{cd}}$ & $11.8 \pm 0.1^{\mathrm{ab}}$ \\
\hline DADS & $83.9 \pm 0.9 \mathrm{bc}$ & $57.1 \pm 2.1^{b}$ & $42.9 \pm 2.1^{c}$ & $15.3 \pm 0.6^{\mathrm{bc}}$ & $7.0 \pm 0.6^{\mathrm{cd}}$ & $11.3 \pm 0.1^{b c}$ & $9.3 \pm 0.5^{\mathrm{ab}}$ \\
\hline DATS & $84.5 \pm 0.8^{b c}$ & $42.1 \pm 1.4^{\mathrm{cd}}$ & $57.9 \pm 1.4^{\mathrm{ab}}$ & $21.7 \pm 0.5^{\mathrm{a}}$ & $9.9 \pm 0.3^{b}$ & $13.1 \pm 0.4^{\mathrm{ab}}$ & $13.2 \pm 0.2^{\mathrm{ab}}$ \\
\hline DMTS & $84.1 \pm 0.7^{b c}$ & $39.8 \pm 1.3^{\mathrm{d}}$ & $60.2 \pm 1.3^{\mathrm{a}}$ & $20.6 \pm 1.9^{a}$ & $12.2 \pm 0.5^{\mathrm{a}}$ & $14.0 \pm 0.1^{\mathrm{a}}$ & $13.4 \pm 0.4^{\mathrm{a}}$ \\
\hline
\end{tabular}

Data followed by different letters in same column are significantly different $(p<0.05)$. Remaining lycopene: the lycopene content in tomato pulp after thermal treatment compared to that of content in raw tomato pulp.

In the case of lycopene, the profile of generated Z-isomers was similar between isothiocyanates and polysulfides; all-E-lycopene transformed into Z-lycopene especially to 5-Z-lycopene. DMTS exhibited a higher performance in isomerization, total Z-isomers (accounted for $60.2 \%$ ) increased by $51.2 \%$ compared with that of the initial one, of which 5-Z-lycopene accounted for $21.7 \%$, almost two times higher than 9-Z-lycopene. The increasing formation of 5-Z-lycopene could be illustrated by its higher thermal stability [22] Compared with control group, the retention rate of lycopene decreased about $80 \%-86 \%$ due to the formation of unstable cis structure with the effect of isothiocyanate or polysulfides. The mechanism of the conversion of all-E-carotenoids to Z-isomers by sulfur-containing compounds may illustrated by the thiyl radicals produced by disulfide bound [22,23]; while the isothiocyanate could promote the isomerization with it's eletrophilicity, which works like iron(III) chloride [23]. Among isothiocyanates, the improvement of total Z-lycopene proportion by DADS was less than those of DATS and DMTS, which indicated that the number of disulfide bound played an important role on the isomerization of PT, PTF, and lycopene. Honda, et al. [23] also found that the Z-isomerization efficiency of lycopene was related to the length of disulfide bound. This may be related to the disproportionate reaction of dialkyl polysulfides at high temperatures. For instance, disproportionation/degradation of DMTS could form DMDS [36], which can further enhance the isomerization reaction.

DMTS and AITC were chosen to use in the following experiments since they were the most effective catalyst for the isomerization of carotenoids in this study and they are commonly found in vegetables and seasonings. 


\subsection{Effect of Concentration of DMTS and AITC on Isomerization and Degradation of PTF, PT, and Lycopene}

The changes in the ratio of each isomer and the content of three carotenoids in tomato pulp with different concentration of DMTS and AITC are shown in Figure 1. The proportion of Z-lycopene rose in tandem with an increasing number of catalysts. Newly formed cis configurations are mainly presented by 5-Z-lycopene, as it is more stable than other isomers. When DMTS was added to tomato pulp as catalyst, the ratio of total Z-isomers was higher than that of AITC at the same concentration, which indicated that the Z-isomerization efficiency of DMTS was stronger than that of AITC. For example, the proportion of all-Elycopene was dropped to $20 \%$ with DMTS at a concentration of $5 \mathrm{mg} / \mathrm{g}$ (as illustrated in Figure 1E), which was less than that of AITC (29\%) (as illustrated in Figure 1F) under the same condition. Moreover, the proportion of each lycopene isomer was barely changed when the concentration exceeded $2 \mathrm{mg} / \mathrm{g}$ tomato pulp. Meanwhile, the content of total lycopene decreased as the quantity of catalysts increased. The total lycopene content in the raw tomato pulp was $142.4 \mu \mathrm{g} / \mathrm{g}$ and decreased to $105.8 \mu \mathrm{g} / \mathrm{g}$ and $107.8 \mu \mathrm{g} / \mathrm{g}$ when $5 \mathrm{mg} / \mathrm{g}$ tomato pulp DMTS and AITC added, respectively.
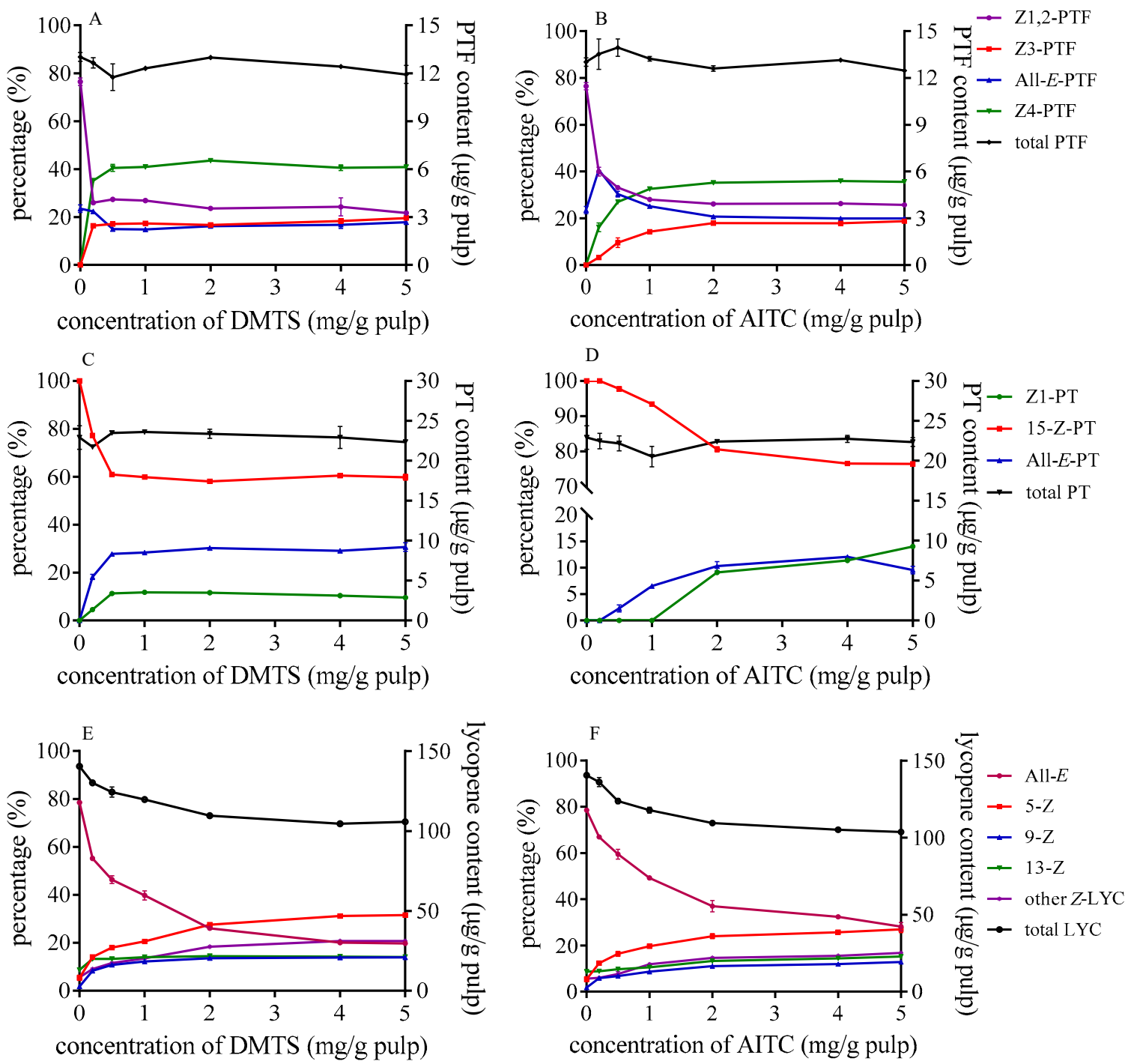

Figure 1. Effect of concentration of DMTS (A,C,E) and AITC (B,D,F) on isomerization and degradation of PTF (A,B), PT, (C,D) and lycopene (E,F); DMTS: dimethyl trisulfide; AITC: allyl isothiocyanate; PTF: phytofluene; PT: phytoene. 
For PTF, the isomerization occurred even at a lower concentration of $0.2 \mathrm{mg} / \mathrm{g}$ with DMTS. Then, with the increase of catalyst concentration, the proportion of each isomer showed no significant changes. However, the proportion of isomers equilibrated at the concentration of $2 \mathrm{mg} / \mathrm{g}$ in the case of AITC (as illustrated in Figure 1B). The predominant isomer was Z4-PTF and accounted for $41 \%$ at the equilibrium, while Z1,2-PTF decreased to $22 \%$ with the effect of DMTS, and the proportions of all-E-PTF showed little change compared with those in raw tomato pulp. Several studies showed that the isomers of PTF could transform to each other during thermal treatment [30], and in the study by Meléndez-Martínez, et al. [32], the last eluted peak of PTF was the main isomers after thermal treatment with iodine. We speculated that Z4-PTF might be the most stable geometric isomer among the five geometric isomers under catalysis. In the case of PT, as the quantity of catalysts increased, 15-Z-PT decreased but all-E-PT and Z1-PT increased. The changes in the relative proportion of PT isomers were inapparent compared with PTF. 15-Z-PT was still the main isomers after heating. When DMTS was added as the catalyst (as illustrated in Figure 1C), the proportion of 15-Z-PT at the equilibrium was about $60 \%$. The effect of AITC was weaker than DMTS, and Z1-PT cannot form when the concentration is less than $1 \mathrm{mg} / \mathrm{g}$. Besides, the total PT and PTF hardly decomposed with the increased concentration of catalysts.

\subsection{Effect of Reaction Temperature on Isomerization and Degradation of PTF, PT, and Lycopene}

Carotenoids were significantly affected by temperature during processing. The changes of three carotenoids in control group without catalysts under different heating temperature are shown in Figure 2. Lycopene was stable enough under $100{ }^{\circ} \mathrm{C}$, and the ratio of lycopene isomers and the remaining content hardly changed. However, lycopene started to degrade, and the proportion of all-E-lycopene decreased to $65 \%$ when the temperature reached $120^{\circ} \mathrm{C}$. Some data showed that addition of olive oil to tomato puree could increase Z-lycopene upon heating at $120^{\circ} \mathrm{C}$ [37]. Concerning PTF, the proportion of all-E-PTF was slightly increased over $80^{\circ} \mathrm{C}$, and there were no newly isomers formed under $120^{\circ} \mathrm{C}$ in control group. As for PT, 15-Z-PT hardly changed with the temperature rise.

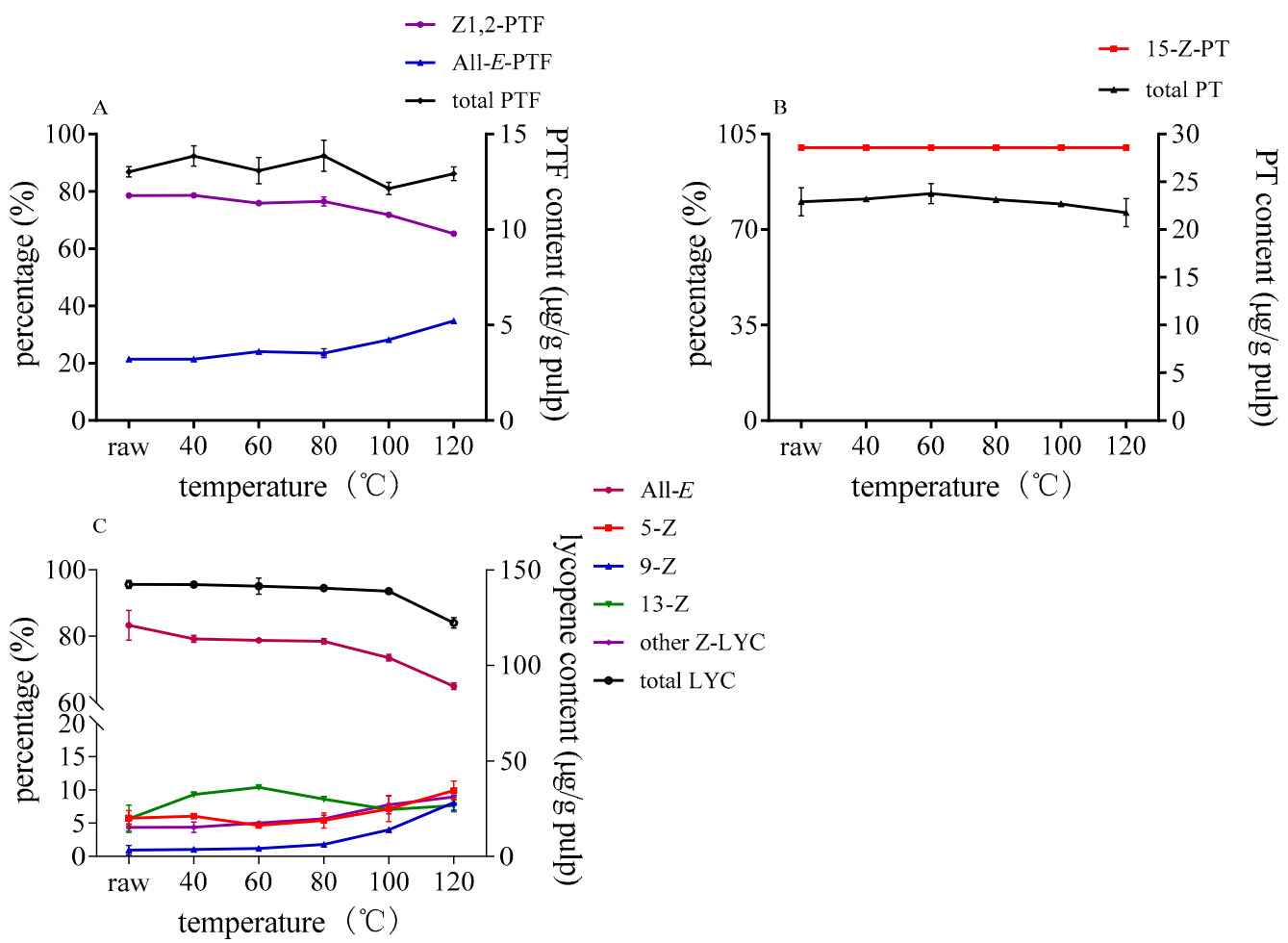

Figure 2. Effect of reaction temperature on isomerization and degradation of PTF (A), PT (B), and lycopene (C) without sulfur-containing compounds. 
The isomerization of lycopene could happen even at a lower temperature of about $40{ }^{\circ} \mathrm{C}$ when catalysts are added (as illustrated in Figure 3). As the temperature rose, the ratio of Z-lycopene increased significantly. Besides, the decomposition of total lycopene progressed as the Z-isomerization occurred. Similarly, the isomerization efficiency of DMTS was stronger than that of AITC under the same temperature. Different from lycopene, there was no significant degradation of PTF and PT as the temperature rose, which indicate that the isomers of PTF and PT remain stable within $120^{\circ} \mathrm{C}$. Once the catalysts were added, the content of Z1,2-PTF decreased, while Z3- and Z4-PTF accumulated when temperature increased. Z1,2-PTF was still the predominant isomer at lower temperature; however, the ratio of Z4-PTF gradually increased as the temperature rose to $120^{\circ} \mathrm{C}$. The content of Z4-PTF took up about $40 \%$ of total PTF in the case of DATS after heating to $120^{\circ} \mathrm{C}$. As for $\mathrm{PT}$, the content of 15-Z-PT significantly decreased and converted to all-E- and Z1-PT as the temperature rose. The higher the temperature was, the more Z1- and all-E-PT accumulated by DMTS (as illustrated in Figure 3C). In the case of AITC, Z1-PTF cannot be formed, even at a higher temperature when the concentration was $1 \mathrm{mg} / \mathrm{g}$ tomato pulp.

A

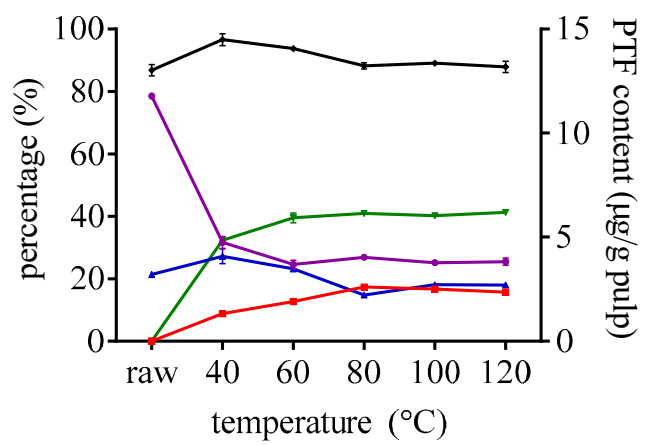

$\mathrm{C}$

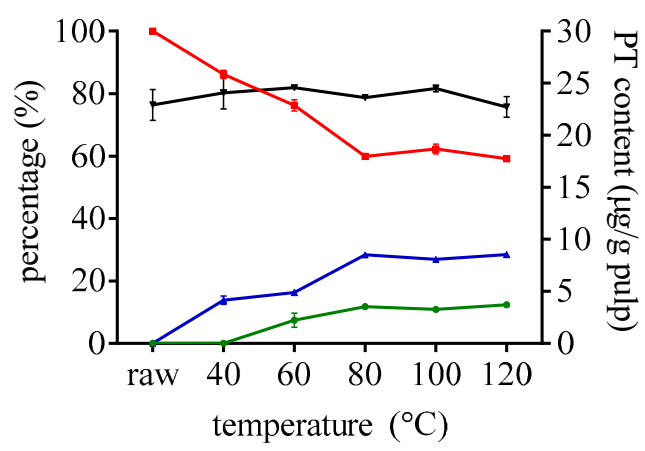

$\mathrm{E}$

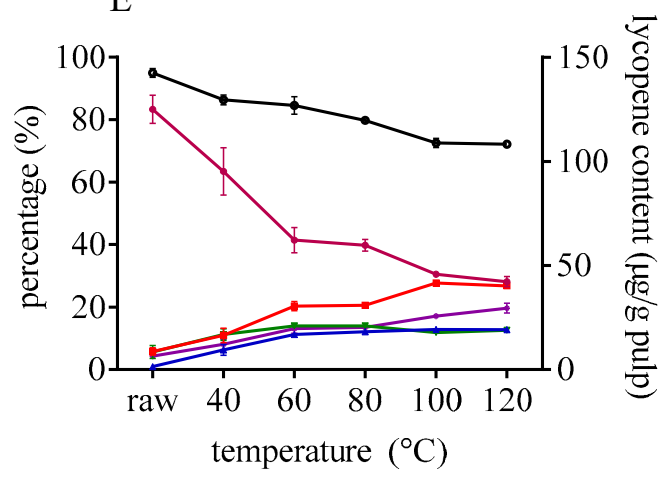

B

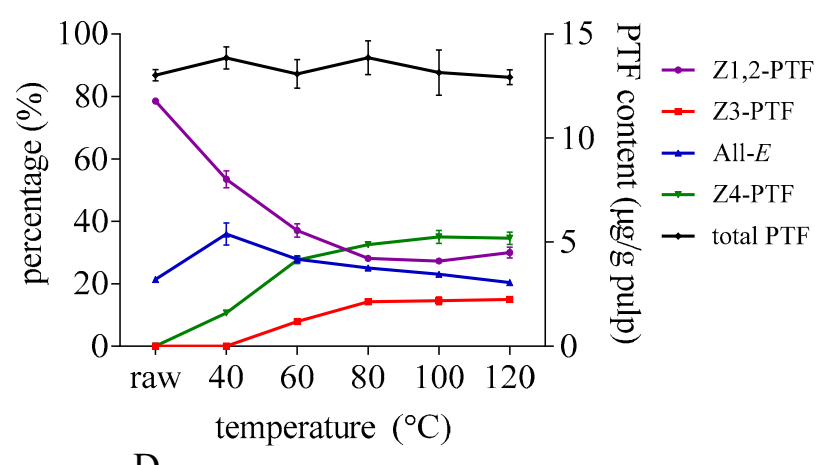

$\mathrm{D}$
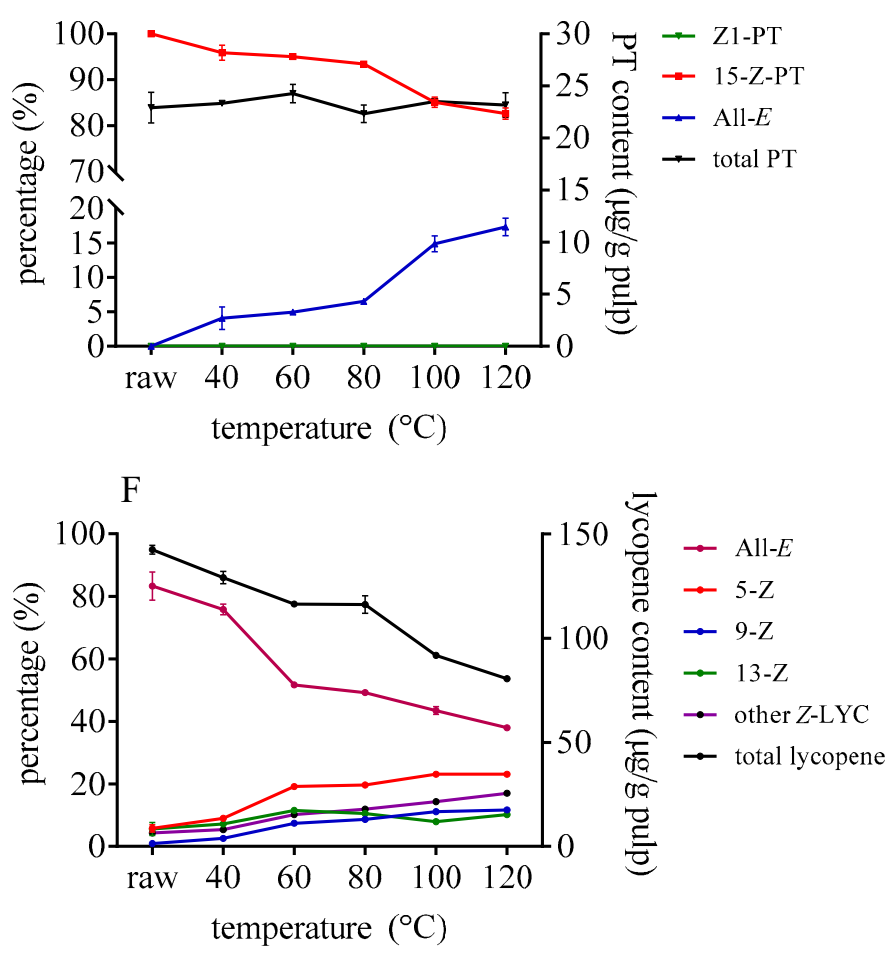

Figure 3. Effect of heating temperature on isomerization and degradation of PTF (A,B), PT (C,D), and lycopene (E,F) with DMTS $(\mathbf{A}, \mathbf{C}, \mathbf{E})$ and AITC (B,D,F). 


\subsection{Effect of the Reaction Time on Isomerization of Lycopene, Phytoene, and Phytofluene}

During heating tomato pulp at $80^{\circ} \mathrm{C}$ from 0 to $120 \mathrm{~min}$, the degradation and isomerization hardly occurred in these three carotenoids without sulfur-containing compounds (as illustrated in Figure 4). Only the proportion of 13-Z-lycopene slightly increased, which was probably because of its lower rotational barriers, as opposed to that of other Z-lycopene [38]. PTF and PT were stable within 120 min under $80^{\circ} \mathrm{C}$ as well. Cooperstone et al. [25] also found that PTF and PT were unchanged when tomato sauce was processed at $100{ }^{\circ} \mathrm{C}$ for 180 min with fat.
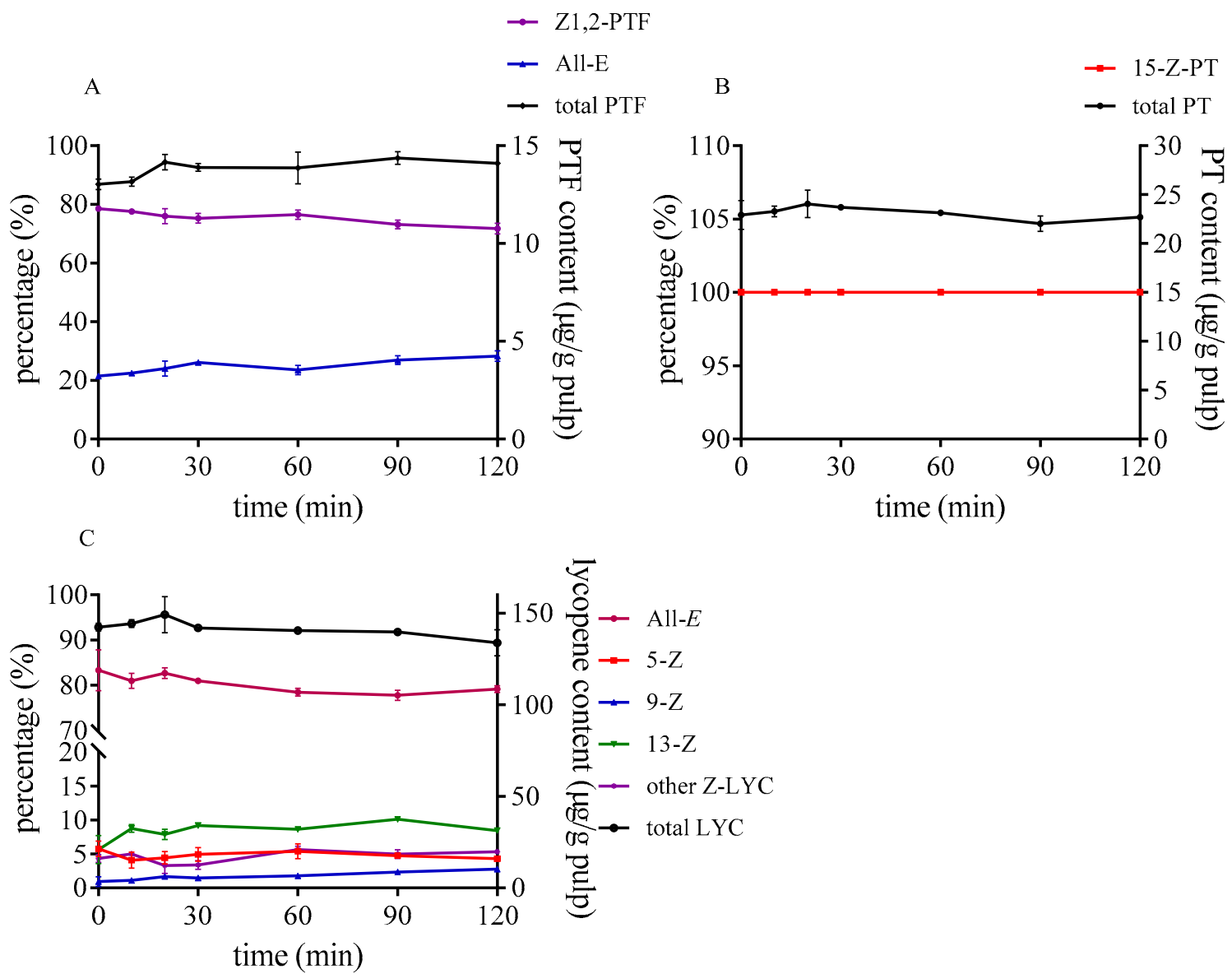

Figure 4. Effect of reaction time on isomerization and degradation of PTF (A), PT (B), and lycopene (C) without sulfurcontaining compounds.

As shown in Figure 5, Z-isomerization of lycopene intensified as reaction time went on when DMTS and AITC were used. The proportion of all-E-lycopene decreased to $33-47 \%$ after $2 \mathrm{~h}$ at $80{ }^{\circ} \mathrm{C}$, and the retention rate of lycopene decreased simultaneously. The remaining lycopene decreased by $25 \%$ when AITC was added compared to that of the control group. In the case of PTF and PT, the original Z-isomers of PTF and PT that existed in tomato were decreased as time progressed. After heating for $60 \mathrm{~min}$, the proportion between PTF isomers hardly changed, and Z4-PTF was the dominant one. Meanwhile, the reduction of 15-Z-PT was more moderate than that of Z1,2-PTF after heat treatment. Specially, Z1-PT cannot be generated when AITC is used, and all-E-PT decreased to 78\% after heating for $120 \mathrm{~min}$. 
A

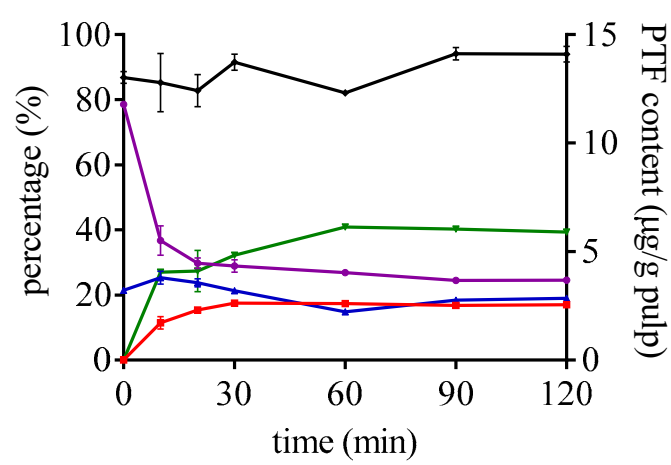

$\mathrm{C}$
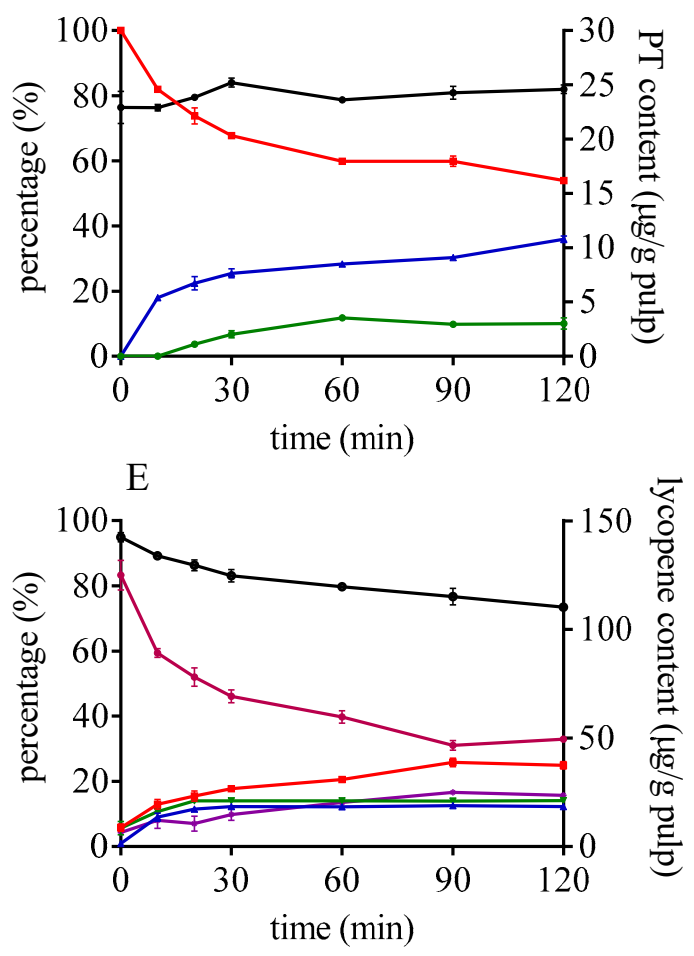

B

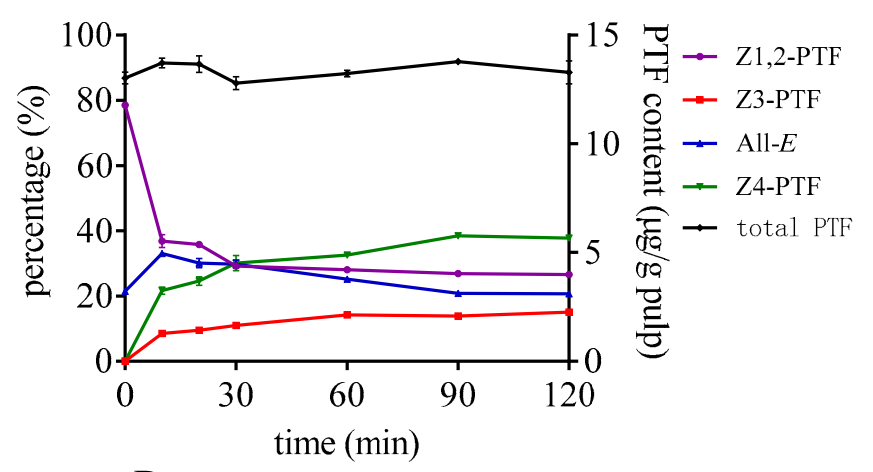

$\mathrm{D}$
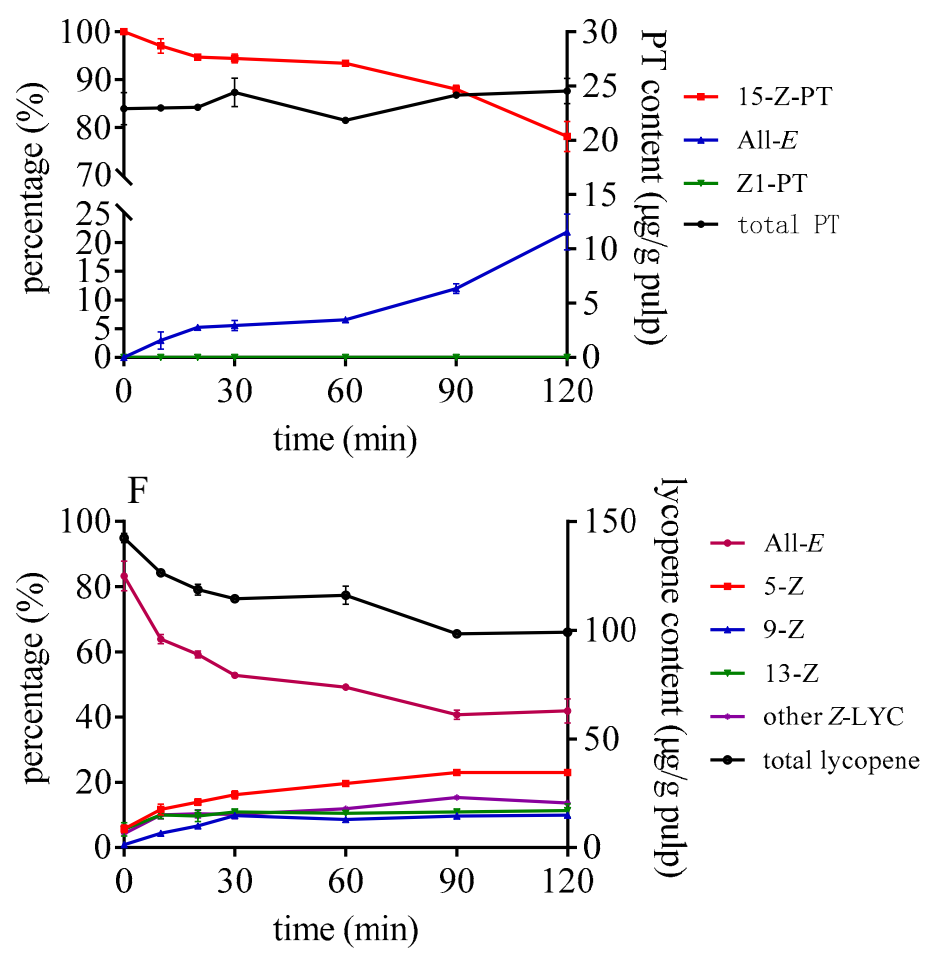

Figure 5. Effect of heating time on the isomerization and degradation of PTF $(\mathbf{A}, \mathbf{B})$, PT $(\mathbf{C}, \mathbf{D})$, and lycopene $(\mathbf{E}, \mathbf{F})$ with DMTS $(\mathbf{A}, \mathbf{C}, \mathbf{E})$ and AITC (B,D,F).

3.6. The Proflies and Bioaccessibility of the Lycopene, Phytoene, and Phytofluene Isomers in Tomato Heated with Shii-Take Mushroom

The isomer constitution and the content of PTF, PT, and lycopene after heat treatment in tomato and shii-take mushroom mixture were showed in Figure 6. The configuration of the three carotenoids changed as act in 3.2 which indicated that the sulfur- containing compounds in shii-take mushroom also had the catalysis effect on PTF, PT, and lycopene. As the added shii-take mushroom increased, the proportion of major naturally occurring Zisomers of PTF and PT decreased. As for lycopene, the ratio of cis-lycopene increased with the addition of shii-take mushroom. The proportion of total cis-lycopene was increased to $40 \%$, and 5-Z-lycopene accounted for $17.9 \%$ after heating with 50\% shii-take mushroom. Similarly, the total content of PTF and PT hardly decreased, while lycopene decomposed as unstable cis-configuration formed. 

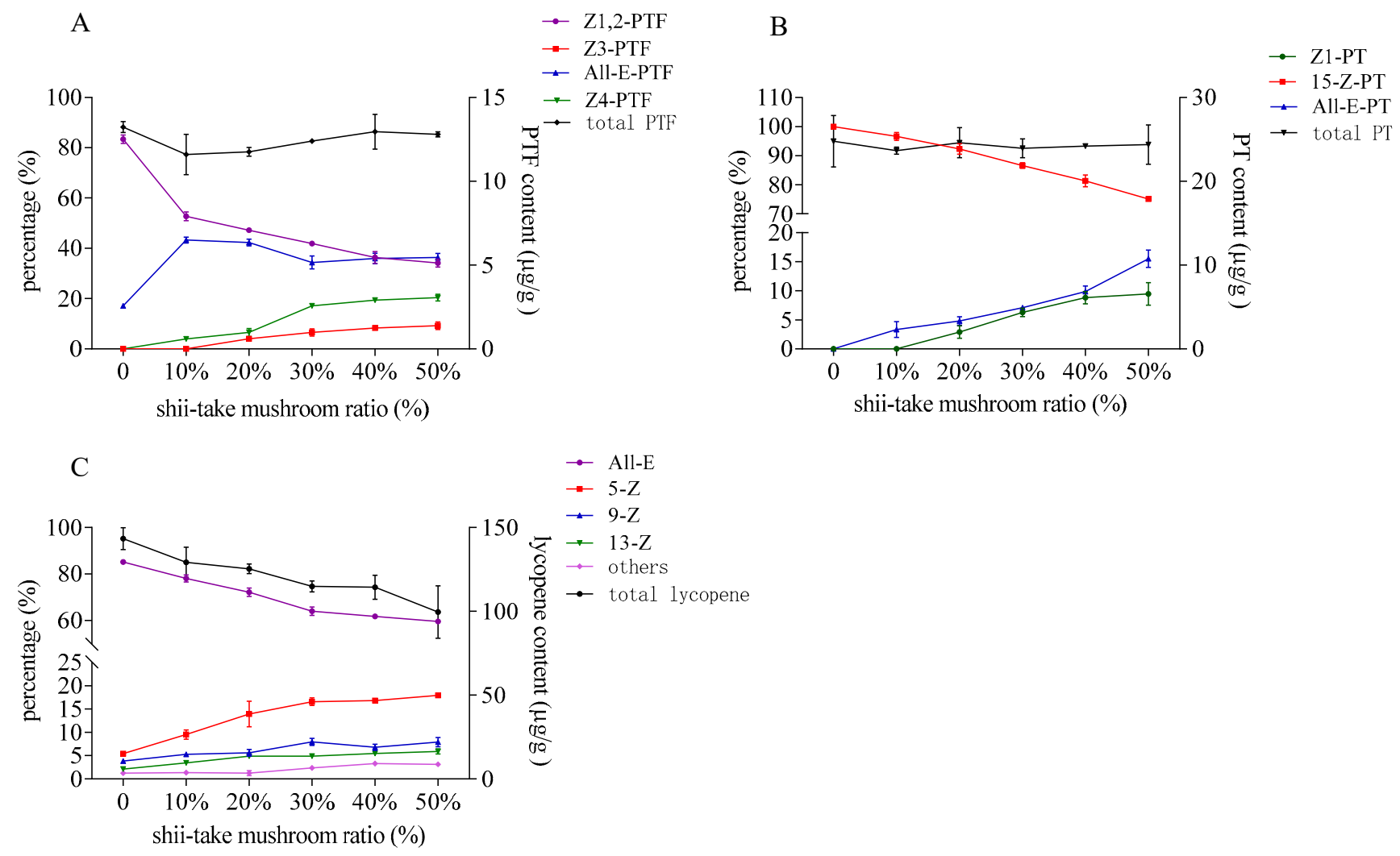

Figure 6. Contents and proportions of phytofluene (A), phytoene (B), and lycopene (C) in tomato with different addition of shii-take mushroom.

Manufacturing process has an effect on the bioaccessibility of carotenoids [13]. Tables 4 and 5 illustrate the bioaccessibility of PTF, PT, and lycopene in tomato shii-take mushroom mixtures after heating at $80^{\circ} \mathrm{C}$ for $1 \mathrm{~h}$. As shown in the tables, the bioaccessibility of PTF and PT (over 20\%) was far more than that of lycopene (1.7\%) without the addition of shii-take mushroom. This can be partially explained by the high micellization efficiency due to the natural existing cis-isomers of PTF and PT [9], while all-E-lycopene forms crystals in chromoplasts.

Table 4. Bioaccessibility (\%) of phytofluene (PTF) and phytoene (PT) in tomato with different addition of shii-take mushroom.

\begin{tabular}{|c|c|c|c|c|c|c|c|c|c|}
\hline \multirow{2}{*}{$\begin{array}{c}\text { Shii-Take } \\
\text { Mushroom } \\
(\%)\end{array}$} & \multicolumn{5}{|c|}{ PTF (\%) } & \multicolumn{4}{|c|}{ PT (\%) } \\
\hline & Total-PTF & Z1,2-PTF & Z3-PTF & All-E-PTF & Z4-PTF & Total-PT & Z1-PT & 15-Z-PT & All-E-PT \\
\hline 0 & $23.25 \pm 0.5^{\mathrm{ab}}$ & $20.36 \pm 0.8^{a b}$ & - & $29.41 \pm 0.3^{\mathrm{a}}$ & - & $25.41 \pm 2.1^{a}$ & - & $25.41 \pm 2.1^{a}$ & - \\
\hline $10 \%$ & $21.61 \pm 0.4^{b}$ & $19.53 \pm 0.3^{b}$ & - & $25.98 \pm 1.2^{\mathrm{a}}$ & $17.03 \pm 1.3^{\mathrm{a}}$ & $25.37 \pm 0.9^{a}$ & - & $25.45 \pm 0.9^{a}$ & $23.32 \pm 1.9^{a}$ \\
\hline $20 \%$ & $24.39 \pm 0.7^{a}$ & $22.67 \pm 1.1^{\mathrm{ab}}$ & $17.07 \pm 1.2^{\mathrm{a}}$ & $28.03 \pm 0.7^{a}$ & $19.90 \pm 1.5^{\mathrm{a}}$ & $24.82 \pm 0.5^{\mathrm{a}}$ & $12.47 \pm 1.7^{\mathrm{ab}}$ & $25.27 \pm 0.6^{\mathrm{a}}$ & $24.15 \pm 0.8^{a}$ \\
\hline $30 \%$ & $23.58 \pm 1.4^{\mathrm{ab}}$ & $21.80 \pm 2.1^{\mathrm{ab}}$ & $17.57 \pm 1.4^{\mathrm{a}}$ & $31.83 \pm 3.1^{\mathrm{a}}$ & $18.48 \pm 0.5^{\mathrm{a}}$ & $23.96 \pm 0.1^{\mathrm{ab}}$ & $7.93 \pm 0.1^{b}$ & $25.24 \pm 0.1^{\mathrm{a}}$ & $22.46 \pm 1.1^{a}$ \\
\hline $40 \%$ & $24.96 \pm 0.6^{\mathrm{a}}$ & $24.06 \pm 0.1^{\mathrm{a}}$ & $17.91 \pm 0.1^{\mathrm{a}}$ & $29.09 \pm 0.8^{a}$ & $23.13 \pm 0.9^{a}$ & $22.04 \pm 0.5^{b}$ & $6.97 \pm 0.2^{b}$ & $24.30 \pm 0.4^{\mathrm{a}}$ & $16.75 \pm 0.1^{b}$ \\
\hline $50 \%$ & $23.96 \pm 0.2^{a b}$ & $23.34 \pm 0.9^{a b}$ & $21.45 \pm 2.6^{a}$ & $27.28 \pm 0.9^{\mathrm{a}}$ & $21.41 \pm 0.3^{a}$ & $19.18 \pm 0.8^{c}$ & $17.87 \pm 0.3^{a}$ & $21.75 \pm 1.2^{\mathrm{a}}$ & $17.36 \pm 0.1^{b}$ \\
\hline
\end{tabular}

Data followed by different letters in same column are significantly different $(p<0.05)$.

In the case of PTF, the bioaccessibility of all-E-PTF was $29.4 \%$, slightly higher than that of Z1,2-PTF. Paula et al. [39] also found that the bioaccessibility of all-E-PTF and PT was slightly higher than that of their cis-isomers, which is illustrated by the molecule competition for incorporation into micelles resulted by the higher concentrations [28]. Moreover, there was no positive effect on the bioaccessibility of PTF and PT with the addition of shii-take mushroom after thermal treatment. The bioaccessibility of total PTF (as illustrated in Table 4) hardly changed, while it decreased significantly $(p<0.05)$ for PT (as illustrated in Table 5) as all-E-PT formed. As for lycopene, the bioaccessibility of lycopene isomers almost decreased in the order: $13-Z>9-Z>5-Z>$ All-E. Z-lycopene 
are more easily transferred into the mixed micelles than all-E-lycopene, which are more likely to aggregate and crystallize [18]. With the increasing addition of shii-take mushroom, the bioaccessibility of total lycopene increased significantly due to the formation of cislycopene. Even though there seems to be a negative effect on the bioaccessibility of PT and PTF with the addition of shii-take mushroom, their bioaccessibilities were still much higher than that of lycopene. Thus, it is necessary to monitor the isomers of colorless carotenoid and lycopene with food-containing natural catalysts to forecast their expected isomeric profiles in foods processing.

Table 5. Bioaccessibility (\%) of lycopene in tomato with different addition of shii-take mushroom.

\begin{tabular}{|c|c|c|c|c|c|}
\hline \multirow{2}{*}{$\begin{array}{c}\text { Shii-Take } \\
\text { Mushroom (\%) }\end{array}$} & \multicolumn{5}{|c|}{ Lycopene (\%) } \\
\hline & Total Lycopene & All-E & $5-Z$ & $9-Z$ & $13-Z$ \\
\hline $0 \%$ & $1.71 \pm 0.2^{\mathrm{e}}$ & $0.74 \pm 0.1^{\mathrm{e}}$ & $4.83 \pm 0.4^{c}$ & $7.48 \pm 1.2^{b}$ & $8.77 \pm 1.1^{b}$ \\
\hline $10 \%$ & $4.00 \pm 0.1^{\mathrm{d}}$ & $2.78 \pm 0.2^{d}$ & $8.12 \pm 0.7^{b c}$ & $7.81 \pm 0.2^{b}$ & $9.04 \pm 1.2^{b}$ \\
\hline $20 \%$ & $4.42 \pm 0.2^{\mathrm{cd}}$ & $3.22 \pm 0.1^{\mathrm{cd}}$ & $7.81 \pm 0.8^{b c}$ & $9.11 \pm 1.6^{b}$ & $7.88 \pm 0.2^{b}$ \\
\hline $30 \%$ & $5.42 \pm 0.4^{\mathrm{c}}$ & $3.69 \pm 0.2^{c}$ & $9.06 \pm 0.8^{b c}$ & $9.98 \pm 0.8^{\mathrm{ab}}$ & $9.24 \pm 0.1^{\mathrm{ab}}$ \\
\hline $40 \%$ & $6.67 \pm 0.4^{b}$ & $4.43 \pm 0.3^{b}$ & $9.49 \pm 0.5^{\mathrm{ab}}$ & $11.58 \pm 1.8^{\mathrm{ab}}$ & $9.37 \pm 1.1^{\mathrm{ab}}$ \\
\hline $50 \%$ & $8.03 \pm 0.5^{\mathrm{a}}$ & $6.30 \pm 0.2^{\mathrm{a}}$ & $11.86 \pm 1.4^{\mathrm{a}}$ & $13.81 \pm 1.2^{\mathrm{a}}$ & $12.89 \pm 1.4^{\mathrm{a}}$ \\
\hline
\end{tabular}

Data followed by different letters in same column are significantly different $(p<0.05)$.

\section{Conclusions}

This study investigated the isomerization and degradation of lycopene, PTF, and PT in tomato pulp with sulfur-containing compounds. Sulfur-containing compounds had the effect on the isomerization of lycopene, PTF, and PT, and increasing the heating temperature, time, and concentration of DMTS and AITC could promote the isomerization reaction effectively. Meanwhile, the isomers of PTF and PT had good thermal stability. Moreover, the bioaccessibility of lycopene could increase significantly with the addition of shii-take mushroom containing sulfur compounds, although this had no positive effect on that of PTF and PT. However, the bioaccessibility of PTF and PT were still far higher than that of lycopene. According to the study, cooking or processing tomatoes with the foods containing sulfur-containing compounds could improve the absorbency of total carotenoids. These findings can provide a reference to forecast their expected isomeric profiles in tomato and other carotenoid-containing manufacturing.

Author Contributions: Conceptualization, L.M. and L.Z.; methodology, L.M. and X.J.; resources, J.Z.; writing —original draft preparation, L.M.; writing—review and editing, C.Y.; visualization, C.Y.; supervision, Q.W.; project administration, L.Z.; funding acquisition, C.Y. and L.Z. All authors have read and agreed to the published version of the manuscript.

Funding: This research was funded by the Natural Sciences Foundation of China (31901654), the Natural Science Foundation of Jiangsu Province (BK20190592), Key Scientific and Technological Project of Xinjiang Uygur Autonomous Region (2019E0273), Science and Technology Project of Xinjiang Production and Construction Corps (2019DB008), and Xinjiang Changji Science and Technology Project (2019G02).

Conflicts of Interest: The authors declare no conflict of interest. 


\section{Appendix A}
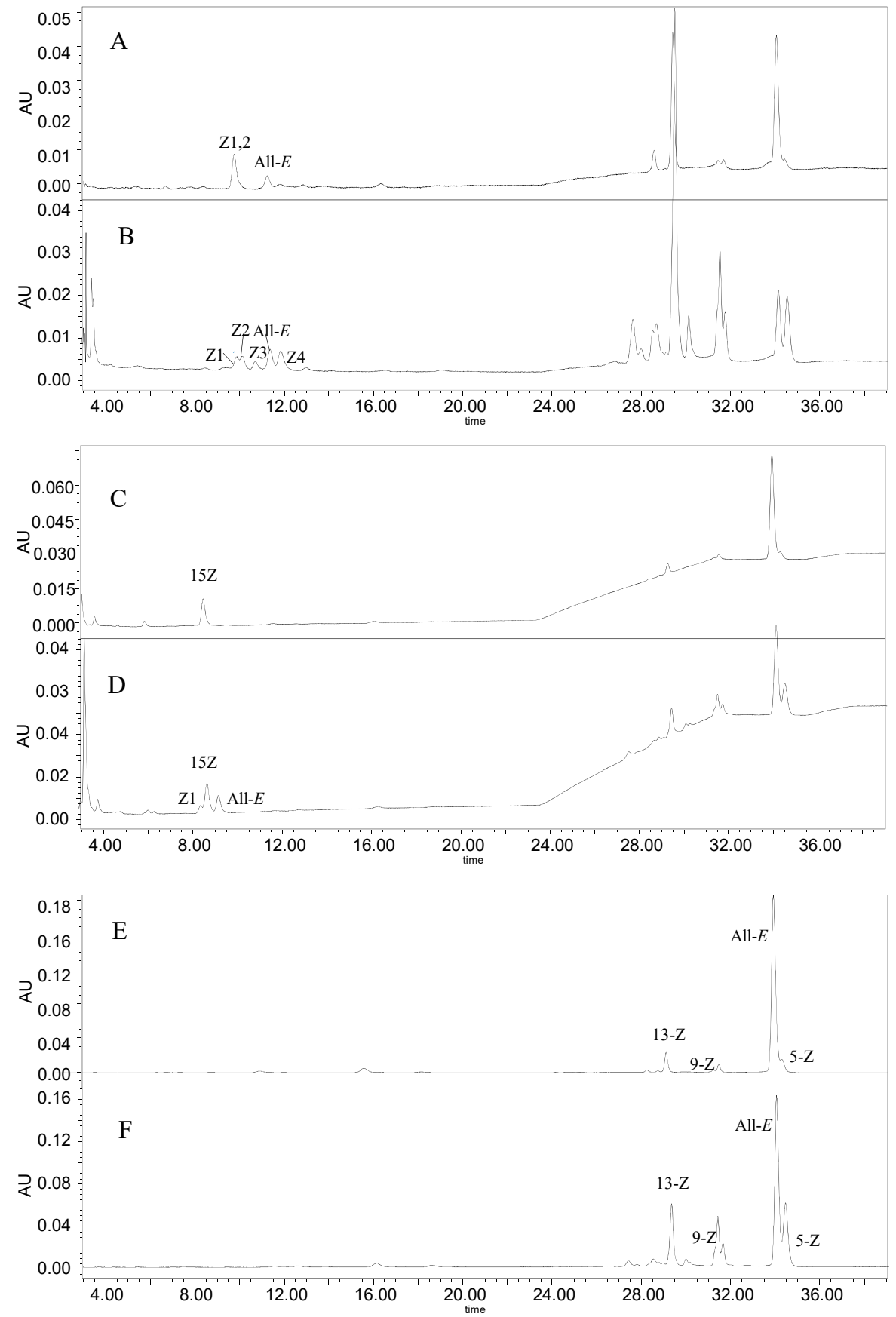

Figure A1. HPLC chromatogram of phytofluene at $348 \mathrm{~nm}(\mathbf{A}, \mathbf{B})$, phytoene at $286 \mathrm{~nm}(\mathbf{C}, \mathbf{D})$, and lycopene at $471 \mathrm{~nm}(\mathbf{E}, \mathbf{F})$ before $(\mathbf{A}, \mathbf{C}, \mathbf{E})$ and after $(\mathbf{B}, \mathbf{D}, \mathbf{F})$ heating at $80^{\circ} \mathrm{C}$ for $1 \mathrm{~h}$ with DMTS. 

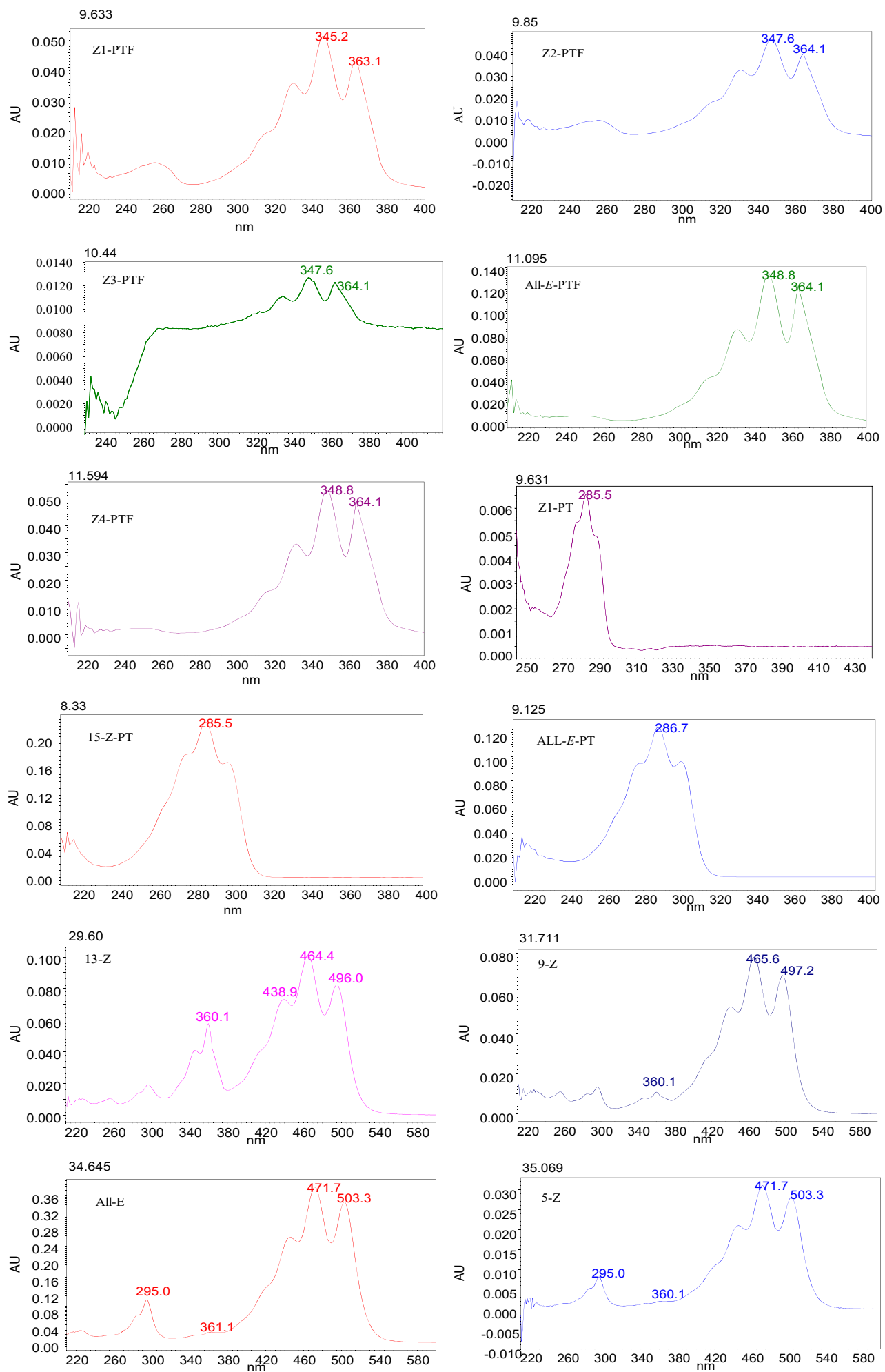

Figure A2. Spectra in mobile phase of main geometric isomers of PTF, PT, and lycopene.

\section{References}

1. Salehi, B.; Sharifi-Rad, R.; Sharopov, F.; Namiesnik, J.; Farjadian, F.; Kamle, M.; Kumar, P.; Martins, N.; Sharifi-Rad, J. Beneficial effects and potential risks of tomato consumption for human health: An overview. Nutrition 2019, 62, 201-208. [CrossRef] [PubMed]

2. Burton-Freeman, B.; Reimers, K. Tomato Consumption and Health: Emerging Benefits. Am. J. Lifestyle Med. 2010, 5, 182-191. [CrossRef] 
3. Giovannucci, E. A Prospective Study of Tomato Products, Lycopene, and Prostate Cancer Risk. J. Natl. Cancer Inst. 2002, 94, 391-398. [CrossRef] [PubMed]

4. Assar, E.A.; Vidalle, M.C.; Chopra, M.; Hafizi, S. Lycopene acts through inhibition of I $\mathrm{kB}$ kinase to suppress NF- $\mathrm{B}$ B signaling in human prostate and breast cancer cells. Tumor Biol. 2016, 37, 9375-9385. [CrossRef]

5. Saini, R.K.; Rengasamy, K.R.; Mahomoodally, F.M.; Keum, Y.-S. Protective effects of lycopene in cancer, cardiovascular, and neurodegenerative diseases: An update on epidemiological and mechanistic perspectives. Pharmacol. Res. 2020, 155, 104730. [CrossRef] [PubMed]

6. Basu, A.; Imrhan, V. Tomatoes versus lycopene in oxidative stress and carcinogenesis: Conclusions from clinical trials. Eur. J. Clin. Nutr. 2006, 61, 295-303. [CrossRef]

7. Biehler, E.; Alkerwi, A.; Hoffmann, L.; Krause, E.; Guillaume, M.; Lair, M.-L.; Bohn, T. Contribution of violaxanthin, neoxanthin, phytoene and phytofluene to total carotenoid intake: Assessment in Luxembourg. J. Food Compos. Anal. 2012, 25, 56-65. [CrossRef]

8. Mapelli-Brahm, P.; Margier, M.; Desmarchelier, C.; Halimi, C.; Nowicki, M.; Borel, P.; Melendez-Martinez, A.J.; Reboul, E. Comparison of the bioavailability and intestinal absorption sites of phytoene, phytofluene, lycopene and $\beta$-carotene. Food Chem. 2019, 300, 125232. [CrossRef]

9. Mapelli-Brahm, P.; Desmarchelier, C.; Margier, M.; Reboul, E.; Martínez, A.J.M.; Borel, P. Phytoene and Phytofluene Isolated from a Tomato Extract are Readily Incorporated in Mixed Micelles and Absorbed by Caco-2 Cells, as Compared to Lycopene, and SR-BI is Involved in their Cellular Uptake. Mol. Nutr. Food Res. 2018, 62, 1800703. [CrossRef]

10. Stinco, C.M.; Heredia, F.J.; Vicario, I.M.; Meléndez-Martínez, A.J. In vitro antioxidant capacity of tomato products: Relationships with their lycopene, phytoene, phytofluene and alpha-tocopherol contents, evaluation of interactions and correlation with reflectance measurements. LWT Food Sci. Technol. 2016, 65, 718-724. [CrossRef]

11. Engelmann, N.J.; Clinton, S.K.; Erdman, J.W. Nutritional Aspects of Phytoene and Phytofluene, Carotenoid Precursors to Lycopene. Adv. Nutr. 2011, 2, 51-61. [CrossRef]

12. Melendez-Martinez, A.J.; Mapelli-Brahm, P.; Stinco, C.M. The colourless carotenoids phytoene and phytofluene: From dietary sources to their usefulness for the functional foods and nutricosmetics industries. J. Food Compos. Anal. 2018, 67, 91-103. [CrossRef]

13. Shi, J. Lycopene in Tomatoes: Chemical and Physical Properties Affected by Food Processing. Crit. Rev. Biotechnol. 2000, 20, 293-334. [CrossRef] [PubMed]

14. Richelle, M.; Lambelet, P.; Rytz, A.; Tavazzi, I.; Mermoud, A.-F.; Juhel, C.; Borel, P.; Bortlik, K. The proportion of lycopene isomers in human plasma is modulated by lycopene isomer profile in the meal but not by lycopene preparation. Br. J. Nutr. 2011, 107, 1482-1488. [CrossRef]

15. Schierle, J.; Bretzel, W.; Bühler, I.; Faccin, N.; Hess, D.; Steiner, K.; Schüep, W. Content and isomeric ratio of lycopene in food and human blood plasma. Food Chem. 1997, 59, 459-465. [CrossRef]

16. Honda, M.; Nakayama, Y.; Nishikawa, S.; Tsuda, T. Z-Isomers of lycopene exhibit greater liver accumulation than the all-E-isomer in mice. Biosci. Biotechnol. Biochem. 2020, 84, 428-431. [CrossRef] [PubMed]

17. Unlu, N.Z.; Bohn, T.; Francis, D.M.; Nagaraja, H.N.; Clinton, S.K.; Schwartz, S.J. Lycopene from heat-induced cis-isomer-rich tomato sauce is more bioavailable than from all-trans-rich tomato sauce in human subjects. Br. J. Nutr. 2007, 98, 140-146. [CrossRef]

18. de Alvarenga, J.F.R.; Tran, C.; Hurtado-Barroso, S.; Martinez-Huélamo, M.; Illan, M.; Lamuela-Raventos, R.M. Home cooking and ingredient synergism improve lycopene isomer production in Sofrito. Food Res. Int. 2017, 99, 851-861. [CrossRef] [PubMed]

19. Rubio-Diaz, D.E.; Santos, A.; Francis, D.M.; Rodriguez-Saona, L.E. Carotenoid stability during production and storage of tomato juice made from tomatoes with diverse pigment profiles measured by infrared spectroscopy. J. Agric. Food Chem. 2010, 58, 8692-8698. [CrossRef]

20. Honda, M.; Kageyama, H.; Hibino, T.; Zhang, Y.; Ichihashi, K.; Fukaya, T.; Goto, M. Impact of global traditional seasonings on thermal Z-isomerization of (all-E)-lycopene in tomato puree. LWT Food Sci. Technol. 2019, 116, 108565. [CrossRef]

21. Honda, M.; Kageyama, H.; Hibino, T.; Takemura, R.; Goto, M.; Fukaya, T. Enhanced Z-isomerization of tomato lycopene through the optimal combination of food ingredients. Sci. Rep. 2019, 9, 1-7. [CrossRef] [PubMed]

22. Yu, J.; Gleize, B.; Zhang, L.; Caris-Veyrat, C.; Renard, C.M. Heating tomato puree in the presence of lipids and onion: The impact of onion on lycopene isomerization. Food Chem. 2019, 296, 9-16. [CrossRef] [PubMed]

23. Honda, M.; Kageyama, H.; Hibino, T.; Ichihashi, K.; Takada, W.; Goto, M. Isomerization of Commercially Important Carotenoids (Lycopene, $\beta$-Carotene, and Astaxanthin) by Natural Catalysts: Isothiocyanates and Polysulfides. J. Agric. Food Chem. 2020, 68, 3228-3237. [CrossRef] [PubMed]

24. Graziani, G.; Pernice, R.; Lanzuise, S.; Vitaglione, P.; Anese, M.; Fogliano, V. Effect of peeling and heating on carotenoid content and antioxidant activity of tomato and tomato-virgin olive oil systems. Eur. Food Res. Technol. 2003, 216, 116-121. [CrossRef]

25. Cooperstone, J.L.; Francis, D.M.; Schwartz, S.J. Thermal processing differentially affects lycopene and other carotenoids in cis-lycopene containing, tangerine tomatoes. Food Chem. 2016, 210, 466-472. [CrossRef] [PubMed]

26. Mapelli-Brahm, P.; Stinco, C.M.; Rodrigo, M.J.; Zacarías, L.; Melendez-Martinez, A.J. Impact of thermal treatments on the bioaccessibility of phytoene and phytofluene in relation to changes in the microstructure and size of orange juice particles. J. Funct. Foods 2018, 46, 38-47. [CrossRef] 
27. Luo, D.; Wu, J.; Ma, Z.; Tang, P.; Liao, X.; Lao, F. Production of high sensory quality Shiitake mushroom (Lentinus edodes) by pulsed air-impingement jet drying (AID) technique. Food Chem. 2021, 341, 128290. [CrossRef]

28. Yu, J.; Gleize, B.; Zhang, L.; Caris-Veyrat, C.; Renard, C.M.G.C. Impact of onions in tomato-based sauces on isomerization and bioaccessibility of colorless carotenes: Phytoene and phytofluene. Food Funct. 2020, 11, 5122-5132. [CrossRef]

29. Melendez-Martinez, A.J.; Stinco, C.M.; Liu, C.; Wang, X.-D. A simple HPLC method for the comprehensive analysis of cis/trans (Z/E) geometrical isomers of carotenoids for nutritional studies. Food Chem. 2013, 138, 1341-1350. [CrossRef]

30. Lu, Q.; Peng, Y.; Zhu, C.; Pan, S. Effect of thermal treatment on carotenoids, flavonoids and ascorbic acid in juice of orange cv. Cara Cara. Food Chem. 2018, 265, 39-48. [CrossRef]

31. Murakami, K.; Honda, M.; Takemura, R.; Fukaya, T.; Wahyudiono; Kanda, H.; Goto, M. Effect of thermal treatment and light irradiation on the stability of lycopene with high Z-isomers content. Food Chem. 2018, 250, 253-258. [CrossRef]

32. Melendez-Martinez, A.J.; Paulino, M.; Stinco, C.M.; Mapelli-Brahm, P.; Wang, X.-D. Study of the Time-Course ofcis/trans(Z/E) Isomerization of Lycopene, Phytoene, and Phytofluene from Tomato. J. Agric. Food Chem. 2014, 62, 12399-12406. [CrossRef] [PubMed]

33. Than, A.; Bramley, P.; Davies, B.; Rees, A.F. Stereochemistry of phytoene. Phytochemistry 1972, 11, 3187-3192. [CrossRef]

34. Colle, I.; Lemmens, L.; Van Buggenhout, S.; Van Loey, A.; Hendrickx, M. Effect of Thermal Processing on the Degradation, Isomerization, and Bioaccessibility of Lycopene in Tomato Pulp. J. Food Sci. 2010, 75, C753-C759. [CrossRef] [PubMed]

35. Colle, I.J.P.; Lemmens, L.; Tolesa, G.N.; Van Buggenhout, S.; De Vleeschouwer, K.; Van Loey, A.M.; Hendrickx, M.E. Lycopene Degradation and Isomerization Kinetics during Thermal Processing of an Olive Oil/Tomato Emulsion. J. Agric. Food Chem. 2010, 58, 12784-12789. [CrossRef] [PubMed]

36. Warnakula, I.K.; Ebrahimpour, A.; Li, S.Y.; Ralalage, R.D.G.; Hewa-Rahinduwage, C.C.; Kiss, M.; Rios, C.T.; Kelley, K.D.; Whiteman, A.C.; Thompson, D.E.; et al. Evaluation of the Long-Term Storage Stability of the Cyanide Antidote: Dimethyl Trisulfide and Degradation Product Identification. ACS Omega 2020, 5, 27171-27179. [CrossRef] [PubMed]

37. Honda, M.; Murakami, K.; Watanabe, Y.; Higashiura, T.; Fukaya, T.; Wahyudiono; Kanda, H.; Goto, M. The E/Z isomer ratio of lycopene in foods and effect of heating with edible oils and fats on isomerization of (all-E)-lycopene. Eur. J. Lipid Sci. Technol. 2017, 119, 1600389. [CrossRef]

38. Guo, W.-H.; Tu, C.-Y.; Hu, C.-H. Cis-Trans Isomerizations of $\beta$-Carotene and Lycopene: A Theoretical Study. J. Phys. Chem. B 2008, 112, 12158-12167. [CrossRef]

39. Paula, M.; Joana, C.; Antonio, J.M.; Bohn, T. Bioaccessibility of phytoene and phytofluene is superior to other carotenoids from selected fruit and vegetable juices. Food Chem. 2017, 229, 304-311. 